\title{
Safety of carotid ligation and its role in the management of intracranial aneurysms
}

\author{
J. DOUGLAS MILLER ${ }^{1}$, K. JAWAD, AND BRYAN JENNETT
}

From the MRC Group for the Study of the Cerebral Circulation, Institute of Neurological Sciences, Glasgow

SUMMARY By using measurements of cerebral blood flow and internal carotid artery pressure it is possible to select patients in whom carotid ligation can be performed with a very low risk of postoperative cerebral ischaemia. A study has been carried out in 100 patients comparing this method with clinical predictions of the type used in aneurysm surgery based on age of the patient, arterial hypertension, time from latest subarachnoid haemorrhage, and neurological status on a modified Botterell scale. These clinical factors were found to be of little value in predicting which patients would and would not develop cerebral ischaemia after carotid occlusion.

Carotid ligation is one of the classical operations of surgery, although indications for the procedure have changed through the years. Originally introduced in 1778 for the treatment of injuries of the neck (Abernethy, 1811), it was first used to treat intracranial aneurysm in 1885 (Keen, 1890). Until the development of cerebral angiography, carotid ligation was performed to treat unruptured aneurysms which had produced neurological signs by pressure on surrounding structures. Angiography made it possible to diagnose aneurysms which had caused subarachnoid haemorrhage. At the same time it had become common practice to undertake intracranial surgery to achieve a direct obliteration of the aneurysm. Some neurosurgeons have continued to use carotid ligation in the treatment of certain aneurysms, mainly those arising from the internal carotid artery, no matter whether the clinical presentation is of local pressure effects or subarachnoid haemorrhage. Others prefer to reserve carotid ligation for aneurysms considered inaccessible or too technically difficult for intracranial surgery. The widespread adoption of the operating microscope, bipolar diathermy, and other advances in surgical technique and neurosurgical anaesthesia have reduced the number of aneurysms deemed inoperable by direct attack, so that there is a growing body of opinion that carotid ligation is an outmoded operation which has little or no place in the repertoire of the contemporary neurosurgeon. It

\footnotetext{
1 Present address: Division of Neurological Surgery, Virginia Commonwealth University, Richmond, Virginia 23298, USA.

Accepted 17 September 1976
}

appears timely, therefore, to review the position to try to define the safety of carotid ligation as perv:formed at present and its role in neurosurger $\bar{s}$ today.

There is now good evidence that carotid ligatio $\frac{?}{\mathrm{p}}$ reduces the incidence of recurrent haemorrhage frope aneurysms of the intracranial portion of the internaf carotid artery to about the same as direct clippingo though this protection may not be permanen (Nishioka, 1966; Tindall, 1973). Ligation of $\overrightarrow{0}$ carotid artery does reduce the options available for $\forall$ further treatment should another aneurysm develop, and this must be counted a disadvantage. Ligation of one carotid artery may even increase the risk of haemorrhage from an aneurysm arising from the opposite carotid tree, although there is no firm evidence for this. All these objections are somewhat hypothetical and the principal controversy concerns the relative risks of ligation and direct clipping in respect of short-term mortality and morbidity; and this in turn is closely related to postoperative cerebral ischaemia. This is one of the most disputed areas of neurosurgery and large multicentre studies have not succeeded in resolving the question, largely because mortality and morbidity in studies of both ligation and direct clipping are consistently greater than those reported by individual surgeons or centres (Paterson, 1968; Jeffreys and Holmes, 1971; Krayenbühl et al., 1972; Graf and Nibbelink, 1974). Surgeons who operate on sufficient aneurysms to have reported personal series large enough to command attention may have exerted intuitive influences on selection and timing of patients for surgery; further bias is likely when series contain a 
large proportion of referral cases. Clearly such surgeons will also have developed special operative skills, which limit the general applicability of their morbidity figures. Whatever the exact reason, the question as to which is the safer method of treatment in an individual patient is unlikely to be resolved solely by further analysis of the data already available in the literature. What is most required is some means of predicting the risk of different methods of management in individual patients.

Neurosurgeons mostly agree that there are certain conditions which are associated with an unfavourable outcome for surgery, and are therefore commonly taken as indications to postpone or avoid operation-either by direct clipping or by carotid ligation. These include neurological impairment, poor clinical state-for example, low grade on the Botterell scale-very recent subarachnoid haemorrhage, the presence of arterial hypertension, or age over 50 years. None of these constitutes an absolute contraindication, however, and most surgeons can recall some excellent results after operations on patients with one or more of these unfavourable features. Equally, however, a tragic outcome may follow the smoothest operation in the most favourable circumstances and most neurosurgeons, although fascinated by the sometimes capricious results of aneurysm surgery, must wish for a way of predictıng individual outcome.

Some 10 years ago we suggested that by measuring the change in regional cerebral blood flow produced by temporary clamping of one carotid artery it might be possible to detect those patients who were liable to develop severe cerebral ischaemia, either immediate or delayed, if the ligation were completed (Jennett et al., 1966). Since then we have used this approach in every patient considered by us for carotid ligation and have introduced several refinements in technique. From our experience in 100 patients we now believe it to be reliable in differentiating between patients who will safely tolerate permanent carotid ligation and those who are likely to develop severe cerebral ischaemia if ligation is carried out.

In previous communications we have compared this approach with various other methods of predicting cerebral ischaemia. Focal EEG slowing during temporary carotid compression showed some correlation with reduced cerebral blood flow in the affected hemisphere in a series of 20 patients. However, we observed on occasions both ischaemia in the absence of EEG slowing, and also EEG slowing in the absence of ischaemia, so that the technique was felt to be unreliable for the prediction of ischaemia in individual patients (Leech et al., 1974).
These observations have now been considerably extended and will be reported in this paper.

Internal carotid artery pressure (ICAP) has been measured in the last 46 patients in the series and confers several advantages when combined with blood flow measurements. When compared with changes in cerebral blood flow (CBF) during carotid compression, however, ICAP measurements were less reliable in predicting cerebral ischaemia of sufficient severity to contraindicate carotid ligation (Leech et al., 1974).

Measurements of several parameters derived from ipsilateral jugular venous blood samples were compared with CBF measurements and proved to be without value in indicating even severe hemisphere ischaemia (Jawad et al., 1976).

Finally, we have compared the preoperative angiographic appearances with $\mathrm{CBF}$ measurements in predicting tolerance of carotid ligation. Spontaneous and compression-induced cross-circulation, wide-bore posterior communicating arteries, and hypoplastic proximal anterior cerebral arteries have each been assessed, and none was found to provide a reliable index of the adequacy of the collateral circulation to cerebral tissue in the event of unilateral carotid occlusion (Jawad et al., 1977).

It appears that measurements of cerebral blood flow and of internal carotid artery pressure during trial occlusion will reliably distinguish between those patients who will, and those who will not, tolerate carotid ligation with safety. It is appropriate now to consider those clinical factors which are thought to influence the outcome of intracranial surgery for aneurysm in the series of patients studied in this way. We hope that this will form a basis for evolving a balanced policy for choosing between carotid ligation and intracranial surgery for certain aneurysms, by establishing the degree of risk involved by each approach.

\section{Methods}

\section{PATIENTS}

The 100 patients in this report were studied during the 10 year period $1965-74$, and consist of a proportion of those patients presenting at the Institute of Neurological Sciences with subarachnoid haemorrhage or with local pressure effects due to aneurysms of the intracranial portion of the internal carotid artery, from the cavernous sinus to the bifurcation. (Carotid ligation has never been recommended by us as treatment for any aneurysm distal to the carotid bifurcation.) The series includes many patients referred by other neurosurgeons in this Institute after a decision had been made that intracranial surgery was either not feasible because of the 
location of the aneurysm, or inadvisable because of the patient's age, presence of multiple aneurysms, or poor general medical condition. The age of the patients ranged from 13 to 69 years, but the peak incidence was in the sixth decade. The distribution of site and presentation of aneurysms, age, neurological status at the time of operation and time from last subarachnoid haemorrhage appear in Tables 1 , 5,6 , and 7 .

Table 1 Aneurysms in patients referred for carotid ligation

\begin{tabular}{lrrl}
\hline & Total & Ruptured & $\begin{array}{l}\text { Local signs only- } \\
\text { not ruptured }\end{array}$ \\
\hline $\begin{array}{l}\text { Single aneurysm } \\
\text { Posterior communicating } \\
\text { artery }\end{array}$ & 52 & 43 & 9 \\
$\begin{array}{l}\text { Internal carotid } \\
\text { bifurcation }\end{array}$ & 10 & 10 & 0 \\
$\begin{array}{l}\text { Intracavernous/siphon } \\
\text { Ophthalmic }\end{array}$ & 8 & 1 & 7 \\
$\begin{array}{l}\text { Multiple aneurysms } \\
\text { Posterior communicating } \\
\quad \text { other }\end{array}$ & 6 & 6 & 0 \\
$\begin{array}{l}\text { Other internal carotid } \\
\text { artery sites }+ \text { other }\end{array}$ & 7 & 16 & 1 \\
\hline & 100 & 81 & 2 \\
\hline
\end{tabular}

\section{PREOPERATIVE ASSESSMENT}

All patients had bilateral carotid angiograms and more than half also had vertebral angiography before the decision concerning surgery. In the last five years of the study the EEG has been recorded during percutaneous carotid compression without anaesthesia as a preliminary screening procedure. If hemiparesis and/or pronounced localised EEG slowing appeared within three minutes, the operative procedure of attempted carotid ligation was postponed and the EEG repeated one or more days later. Less than five patients have been rejected from the study because of persistent severe EEG changes at this stage. Patients tolerating percutaneous carotid compression, which we now check using a pulsemeter attached to the appropriate ear lobe, were scheduled for surgical exposure of the carotid bifurcation and trial clamping on the following day. An assessment of neurological status was made using the Botterell scale, in a modified form; grade 4 was used only for patients with major neurological signs, neither age nor hypertension being taken into account (Botterell et al., 1956).

\section{INTRAOPERATIVE MEASUREMENTS}

The carotid bifurcation was exposed and a catheter passed up the internal carotid artery for injection of ${ }^{133}$ Xenon in saline. Cerebral blood flow was measured by the clearance of ${ }^{133}$ Xenon from the brain as described in our previous publications (Wyper and Rowan, 1973; Leech et al., 1974; Jawad et al., 1976; Jawad et al., 1977). Details of measurement of other physiological variables (systemic and internal carotid arterial pressure, arterial blood gases, end-tidal $\mathrm{CO}_{2}$, and body temperature and EEG) have also been reported previously (Leech et al., 1974).

The first 23 patients were operated on under local anaesthesia; control of arterial $\mathrm{PCO}_{2}$ was less good and variations in cerebral blood flow were rather greater in this group of patients than in those subsequently opeiated on under general anaesthesia. It has therefore become our policy to operate on all patients under light general anaesthesia (nitrous oxide; oxygen plus analgesic agents) with artificial ventilation using muscle relaxants. This is less stressful for the patient and provides steady state conditions in which accurate, repeatable measurements of cerebral blood flow can be made using isotope clearance (Rowan et al., 1975). It is an indication of the confidence which we have in this technique that we now believe it is entirely safe to forego the opportunity of testing speech, limb power, and sensation during periods of temporary carotid occlusion, the traditional method of assessing tolerance of carotid ligation.

We place great importance on the maintenance of steady state conditions during the procedure with respect to arterial $\mathrm{PCO}_{2}$ (less than $2 \mathrm{mmHg}$ variation), $\mathrm{PO}_{2}$, body temperature, systemic arterial pressure, and depth of anaesthesia. After a control measurement of cerebral blood flow in the frontal, temporal, and parietal regions of the appropriate hemisphere all patients had trial clamping of the common carotid artery and/or the internal carotid artery; when both were studied, it was in sequence, with an additional control measurement of flow during the release of the clamp after the first artery had been occluded temporarily. Based on the changes in cerebral blood flow produced by carotid clamping and release of the clamp after the first artery has been occluded and, since 1971, changes in internal carotid artery pressure, a decision was made whether or not to convert the temporary clamp on the carotid artery to a permanent ligation.

The criteria used in deciding whether or not to ligate the carotid artery have been modified during the study. Until 1971 ligation was usually carried out only if the reduction in CBF from control was less than $25 \%$ during temporary clamping. The low incidence $(14 \%)$ of post-ligation hemiplegia was gratifying, but a rather large number of patients were rejected for permanent ligation $(41 \%)$. These patients were either treated by intracranial surgery 
or left unprotected against recurrent subarachnoid haemorrhage. The blood flow criteria were modified in 1971 by account being taken also of changes in internal carotid artery pressure. This reduced the number rejected for ligation from $41 \%$ to less than $20 \%$ with no increase in morbidity; there was, in fact, a decrease. These modified criteria are shown in Table 2. Our experience after three years use of these is that no further modification is possible, because all patients who have been close to the limit in terms of the revised CBF criteria for ligation have also been neurologically unstable in the first three days after ligation, with temporary hemiparesis sometimes appearing in association with episodes of even mild transitory hypoxia or arterial hypotension. Not one of the last 40 patients whom we have ligated has developed persisting cerebral ischaemia, however.

\section{Table 2 Criteria for completion of carotid ligation}

1. Ligation is safe if CBF $>40 \mathrm{ml} / \mathrm{min} / 100 \mathrm{~g}$ during carotid clamping regardless of change from control flow.

2. Ligation is safe if CBF during clamping lies in range $20-40 \mathrm{ml} / \mathrm{min}$. $100 \mathrm{~g}$ provided that the reduction from control flow is $<25 \%$

3. Ligation is also safe in CBF range $20-40 \mathrm{ml} / \mathrm{min}$. $100 \mathrm{~g}$ with up to $35 \%$ reduction in flow from control provided that internal carotid artery pressure $>60 \mathrm{mmHg}$ in normotensive patients.

4. Ligation always unsafe if CBF during clamping $<20 \mathrm{ml} / \mathrm{min} .100 \mathrm{~g}$ regardless of change from control flow.

POSTOPERATIVE ASSESSMENT

After all operations on the carotid bifurcation, whether or not these were followed by permanent occlusion of the carotid artery, patients were nursed flat and observed closely for at least $\mathbf{4 8}$ hours in the intensive care unit. Early rehydration was encouraged and all patients were examined carefully and frequently for the presence of any focal neurological deficit, however slight. When a deficit was encountered, it was graded as temporary if all signs had cleared completely at the time of discharge from the neurological unit, usually seven to 10 days after surgery. Included in this category were all transient disturbances of consciousness, language, or vision which might conceivably have been related to cerebral ischaemia. Prolonged post-ligation neurological deficits consisted of those which persisted beyond the time of discharge although most had cleared up in the following three to six months. This nomenclature does not include oculomotor nerve lesions, as these preceded carotid ligation.

\section{ANALYSIS OF DATA}

We have compared both the frequency of completed carotid ligation and the outcome after completed or attempted ligation against the principal factors which are considered to influence decisions for or against surgical treatment of intracranial aneurysms - namely, the age of the patient, the time from the latest subarachnoid haemorrhage, the presence of arterial hypertension, and neurological status as assessed using the modified Botterell scale. We have also compared the incidence of focal slowing of the EEG in the appropriate hemisphere with the presence of ischaemic levels of cerebral blood flow during carotid clamping.

Our goal has been primarily to determine the safety of carotid ligation by using these techniques of monitoring to detect the risk of cerebral ischaemia. This report is not intended as an evaluation of the therapeutic effectiveness of the procedure. Nevertheless, in the longer term follow-up of the patients in whom ligation was carried out we have recorded the outcome of oculomotor nerve palsy, the incidence of recurrent subarachnoid haemorrhage, and changes in the size of the aneurysm in the limited number of patients who had appropriate follow-up angiography.

We have chosen to study the patients as a single group in making these comparisons, although criteria for ligation have been modified to some extent during the study. We feel this is permissible because the conclusions we draw are the same when smaller subgroups are examined, and because the same situation holds also in many reported series of directly operated intracranial aneurysms when modifications of medical and surgical therapy often occur during the course of a single series.

\section{Results}

\section{CLINICAL FEATURES}

According to the criteria operating at the time, 73 patients were accepted for permanent ligation and 28 were rejected because of excessive reduction in CBF during temporary carotid clamping. This overall rejection rate of $28 \%$ has been reduced during the study from 40 to $20 \%$, but at the time of writing $20 \%$ appears to be a final figure. Of the 72 patients treated by ligation, the overall incidence of temporary cerebral ischaemia was $21 \%$ and of prolonged ischaemia $5 \%$. The incidence of ischaemic deficits was higher in the 28 patients who were rejected for ligation (32\% temporary; $11 \%$ prolonged; Table 3). This is evidence that the CBF measurement does, in fact, select out bad risk cases, because in this latter group of 28 patients the carotid occlusion was only temporary, consisting of one, or at most two, 15 minute periods of carotid clamping.

Of the 28 patients rejected for carotid ligation only 10 were subsequently treated by craniotomy and direct clipping of the aneurysm, and six of them died or were permanently and severely disabled. It 
Table 3 Ischaemic complications after completed and attempted carotid ligation

\begin{tabular}{|c|c|c|c|c|c|}
\hline \multirow{3}{*}{$\begin{array}{c}\text { Entire series } \\
\text { Ligated } \\
\text { Rejected }\end{array}$} & \multirow{2}{*}{$\begin{array}{l}\text { Total } \\
\text { no. }\end{array}$} & \multicolumn{4}{|c|}{ Cerebral ischaemia } \\
\hline & & \multicolumn{2}{|c|}{$\begin{array}{l}\text { Temporary } \\
\text { (no.) (\%) }\end{array}$} & \multicolumn{2}{|c|}{$\begin{array}{l}\text { Prolonged } \\
\text { (no.) }(\%)\end{array}$} \\
\hline & $\begin{array}{l}72 \\
28\end{array}$ & $\begin{array}{r}15 \\
9\end{array}$ & $\begin{array}{l}21 \\
32\end{array}$ & $\begin{array}{l}4 \\
3\end{array}$ & $\begin{array}{r}5 \\
11\end{array}$ \\
\hline Total & 100 & 24 & & 7 & \\
\hline $\begin{array}{c}\text { ICAP series } \\
\text { Ligated } \\
\text { Rejected }\end{array}$ & $\begin{array}{r}37 \\
9\end{array}$ & $\begin{array}{l}5 \\
3\end{array}$ & $\begin{array}{l}14 \\
33\end{array}$ & $\begin{array}{l}0 \\
1\end{array}$ & $\begin{array}{r}0 \\
11\end{array}$ \\
\hline Total & 46 & 8 & 19 & 1 & 2 \\
\hline
\end{tabular}

may be that patients who cannot tolerate carotid ligation are also at increased risk from intracranial surgery; perhaps this also can depend on an adequate collateral circulation to compensate for vessels sacrificed at operation, or subsequently undergoing thrombosis.

\section{RELATIONSHIP BETWEEN EEG AND CBF}

In a previous report based on 20 patients (who are also included in the present larger series) we concluded that focal EEG slowing was not a fully reliable predictor of ischaemia during carotid clamping. We have now analysed data from 84 patients in whom satisfactory EEG recordings were available during carotid clamping with CBF measurement. With group analysis there was a significant correlation between focal EEG slowing - that is, descent of the predominant rhythm into the theta and delta ranges, confined to the side of the brain affected by the carotid clamp-and rejection for carotid ligation based on low values of CBF $(\mathrm{P}<0.001 ;$ Table 4). Mean $\mathrm{CBF}$ during carotid

Table 4 Patients who developed focal EEG slowing during temporary carotid clamping

\begin{tabular}{lll}
\hline 1. Ligated permanently & $7 / 61$ & $11 \%$ \\
Rejected for ligation & $15 / 23$ & $65 \%$ \\
P & $<0.001$ & \\
& & \\
2. No clinical ischaemia & $10 / 70$ & $14 \%$ \\
Clinical ischaemia (immediate or delayed) & $12 / 14 \quad 86 \%$ \\
P & $<0.001$ \\
\hline
\end{tabular}

clamping in 22 patients who developed focal EEG slowing $(23.6 \pm 2.22(\mathrm{SE}) \mathrm{ml} / \mathrm{min} / 100 \mathrm{~g})$ was significantly lower $(\mathrm{P}<0.001)$ than clamped CBF in the remaining 62 patients $(38.3 \pm 1.6 \mathrm{ml} / \mathrm{min} / 100 \mathrm{~g})$. It is also true that of the seven patients in whom carotid ligation was carried out despite focal EEG slowing (according to $\mathrm{CBF}$ criteria) signs of postoperative cerebral ischaemia were seen in five. However, ischaemia was permanent in only one patient, transient in four patients, and did not occur at all in two patients.

We could not find a ranking correlation between the graded severity of EEG changes and the clamped $\mathrm{CBF}$ values, and there was no statistical relationship between clamped internal carotid artery pressure and the presence or absence of EEG slowing. The range of CBF values at which EEG slowing was seen was $12-39 \mathrm{ml} / \mathrm{min} / 100 \mathrm{~g}$, representing reductions from control of $22-74 \%$. We have, however, observed CBF values as low as $13 \mathrm{ml} / \mathrm{min} / 100 \mathrm{~g}$ and reductions as great as $69 \%$ without EEG slowing. Finally, in nine of the patients who developed temporary or permanent cerebral ischaemia after completed carotid ligation, the EEG showed no change throughout the period of trial clamping and CBF measurement.

Thus EEG slowing was not consistently observed during carotid clamping in patients who by our CBF criteria were at risk from cerebral ischaemia; nor was it always found in patients who did develop clinical ischaemia. But EEG slowing was seen in some patients who withstood carotid ligation without developing clinical cerebral ischaemia. It is true that the majority of these patients were being monitored under light general anaesthesia, which may account for some insensitivity of the EEG pattern to alterations in cerebral blood flow and oxidative metabolism. Nevertheless, we must conclude from this study that, while the EEG can reliably detect disastrous cerebral ischaemia, it is not a fully dependable method of identifying all patients at risk from ischaemia, and that it may erroneously predict cerebral ischaemia in some cases.

\section{INFLUENCE OF AGE ON CAROTID LIGATION}

Although control values of CBF were lower and control values of ICAP were higher in older patients ( $>50$ years), the rate of rejection for permanent ligation $(28 \%)$ was identical in those under 50 years $(28 \%)$. We did not find any statistically significant relationship between increasing age and intolerance of carotid ligation (Table 5). In parallel with this finding, we noted that the changes in CBF and ICAP in older patients were closely comparable with those seen in younger age groups. There was no relationship evident between age of the patient and the incidence of temporary or prolonged ischaemia after completed or attempted ligation.

TIME FROM LATEST SUBARACHNOID HAEMORRHAGE The rate of rejection for carotid ligation was higher $(37 \%)$ in those patients in whom ligation was at- 
Table 5 Influence of age on rates of acceptance and rejection for carotid ligation

\begin{tabular}{llllllll}
\hline & \multicolumn{1}{l}{ Years } & & & & \\
& $<20$ & $21-30$ & $31-40$ & $41-50$ & $51-60$ & $61-70$ \\
\hline Ligated* & 4 & 8 & 15 & 9 & 24 & 12 \\
Rejected & 0 & 0 & 7 & 7 & 9 & 5 \\
\hline Total & 4 & 8 & 22 & 16 & $\underbrace{33}_{14 / 50}$ & $28 \%$ & NS \\
Rejected & & $14 / 50$ & $28 \%$ & & 17 & N
\end{tabular}

* No significant difference in age distribution of ligated compared with rejected patients.

tempted during the first seven days from the latest subarachnoid haemorrhage than in those patients in whom it was attempted later $(25 \%)$. Again, however, there was not a statistically significant relationship between time since haemorrhage and tolerance of carotid ligation (Table 6). Nor was there any relationship with the incidence of postoperative cerebral ischaemia.

Table 6 Influence of interval to operation since last subarachnoid haemorrhage on rates of acceptance and rejection for carotid ligation

\begin{tabular}{|c|c|c|c|c|c|}
\hline & \multicolumn{5}{|c|}{ Days } \\
\hline & $0-3$ & $4-7$ & $8-14$ & $15-21$ & 21 \\
\hline Ligated* & 2 & 13 & 23 & 11 & 7 \\
\hline Rejected & 1 & 8 & 10 & 1 & 3 \\
\hline Total & 3 & 21 & 33 & 12 & 10 \\
\hline Rejected & \multicolumn{2}{|c|}{$9 / 2437 \%$} & \multicolumn{3}{|c|}{$14 / 5525 \%$} \\
\hline
\end{tabular}

* No significant difference between ligated and rejected patients.

\section{NEUROLOGICAL GRADING AT TIME OF ATTEMPTED}

\section{CAROTID LIGATION}

There was a barely significant $(\mathrm{P}<0.05)$ increase in the rate of rejection for carotid ligation in patients who were grades 2,3 , and 4 at the time of attempted carotid ligation $(39 \%)$ compared with grade 1 patients, in whom the rejection rate was only $18 \%$. If each grade is taken separately, however, there is not a significant correlation between grade and intolerance of carotid ligation. In fact, the four patients who were in grade 4 at the time of surgery tolerated carotid ligation with no increase in neurological deficit (Table 7). Again, there was no significant correlation between grade and incidence of postoperative ischaemia.
Table 7 Clinicalgrading (modified Botterell) at time of operation

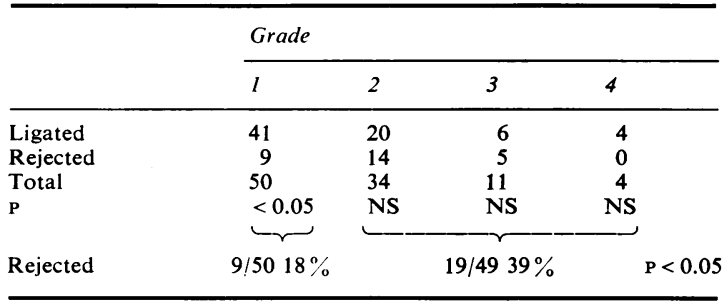

\section{MULTIPLE FACTORS}

We have evaluated various combinations of four factors all of which are normally considered unfavourable in influencing the outcome of aneurysm surgery: (1) age over 50 years, (2) an interval of less than seven days between the latest subarachnoid haemorrhage and attempted/completed carotid ligation, (3) diastolic blood pressure over $100 \mathrm{mmHg}$, and (4) a clinical grade lower than 1 at the time of surgery.

Only if three or more of these factors were present in combination was there a significantly greater rate of rejection $(62 \%: \mathrm{P}<0.01)$ for permanent carotid ligation based on the blood flow studies, but this combination was present in only $13 \%$ of the patients. There was a barely significant increase in the rejection rate in patients over 50 years of age who were at grades 2,3 , or 4 on the modified Botterell scale $(45 \%: \mathrm{P}<0.05)$ but again this category included only $22 \%$ of the patients. The rejection rate for ligation was not significantly increased with any other combination of 'adverse' factors (Table 8).

This analysis suggests that intolerance of carotid

Table 8 Influence of combinations of four unfavourable factors (age $>50$ years, Botterell grade 2 or greater, less than seven days since last subarachnoid haemorrhage, diastolic blood pressure $>100 \mathrm{mmHg}$ ) on rates of acceptance and rejection for carotid ligation

\begin{tabular}{|c|c|c|c|c|c|}
\hline & \multicolumn{5}{|c|}{ Number of factors } \\
\hline & 0 & 1 & 2 & 3 & 4 \\
\hline $\begin{array}{l}\text { Ligated* } \\
\text { Rejected }\end{array}$ & $\begin{array}{r}17 \\
3\end{array}$ & $\begin{array}{r}27 \\
9\end{array}$ & $\begin{array}{r}23 \\
7\end{array}$ & $\begin{array}{l}4 \\
6\end{array}$ & $\begin{array}{l}1 \\
2\end{array}$ \\
\hline Total & 20 & 36 & 30 & 10 & 3 \\
\hline Rejected & \multicolumn{3}{|c|}{$19 / 8622 \%$} & \multicolumn{2}{|c|}{$8 / 1362 \% \quad P<0.01$} \\
\hline
\end{tabular}

* No significant difference between ligated and rejected patients. 
ligation cannot be predicted reliably on clinical grounds alone.

\section{LATE RESULTS}

Of the 72 patients who had carotid ligation completed, four suffered a recurrent subarachnoid haemorrhage, in three cases from aneurysms other than the one for which ligation was done. In two patients necropsies revealed ruptured vertebral artery aneurysms; one of these patients had had vertebral angiography which failed to disclose the lesion. In the third patient recurrent haemorrhage was from a small anterior communicating artery aneurysm which had not been seen on the original angiogram. The fourth patient, with a posterior communicating artery aneurysm, bled again from the same aneurysm; follow-up angiography disclosed that the ligatures on the carotid artery were no longer occluding the lumen of the vessel completely, contrast medium passing two areas of stenosis to fill the aneurysm. This patient is the only one in this series who suffered recurrent haemorrhage from the aneurysm which carotid ligation had been carried out to protect. Of 24 patients who were recognised at the time of surgery to have other aneurysms, none has suffered a recurrent subarachnoid haemorrhage despite the fact that several of these aneurysms must be considered unprotected by the unilateral carotid ligation.

Oculomotor nerve palsy was a feature in 24 patients who had carotid ligation, of whom we have followed up 17 over a prolonged period. Six patients have had complete restoration of eye opening, pupillary size and response and subjective loss of diplopia (some strabismus could still be detected on upward gaze in three patients); in a further 11 patients there has been substantial subjective and objective improvement but oculomotor dysfunction is still obvious on examination. Thus, in every patient who has been followed up, some amelioration of the signs of oculomotor palsy has been seen after carotid ligation.

Follow-up angiography with visualisation of the intracranial portion of the appropriate carotid artery has been possible in only 10 patients. The aneurysm failed to fill in five patients, was decreased in size in three patients, and unchanged in the remaining two.

\section{Conclusions}

The use of cerebral blood flow measurements under tightly controlled and standardised physiological conditions allows patients suitable for permanent carotid ligation to be identified with a very low degree of risk. In the last 40 consecutive patients who have had ligation carried out there has been no mortality and no patient has developed prolonged neurological deficit. Successful carotid ligation has in our experience conferred good protection against recurrent haemorrhage from the aneurysm and satisfactory improvement in oculomotor palsy.

About one patient in five is identified by this procedure as being at risk from cerebral ischaemia if ligation were to be completed. It appears that such patients also fare rather badly when subsequently treated by direct intracranial surgery, but our numbers are as yet too small for statistical analysis.

Considered singly, none of the clinical factors commonly believed to influence the outcome of direct aneurysm surgery (age, time since last haemorrhage, neurological status) were reliably predictive of intolerance to carotid ligation. Combinations of factors which yielded better prediction of ischaemic risk were present in only a small number of patients. Thus, given a suitably located aneurysm, it is almost always worth while attempting carotid ligation, with the proviso that measurements of cerebral blood flow and internal carotid artery pressure are available to identify the risk factor in the individual patient.

\section{Comment}

The low mortality and morbidity of carotid ligation in selected patients with aneurysms of the intracranial portion of the carotid artery ought to be considered by the surgeon contemplating direc clipping of such aneurysms. With certain aneurysms, such as those arising near the origin of the posterior communicating artery, equally good figures are obtainable by direct surgery (Paterson, 1968), although the overall results of the co-operative study from several centres were less good (Graf and Nibbelink, 1974). With other aneurysms, notably those arising from the medial side or superior aspect of the carotid artery, near the ophthalmic artery, intracranial operative results are less good (Sengupta, 1972).

The use of measurements of cerebral blood flow to detect patients with a vulnerable cerebral circulation could be of considerable importance in making decisions not only concerning carotid ligation but also about intracranial surgical risk factors. Clearly it would be a great advantage if such measurements could be made without requiring surgical exposure of the carotid arteries in the neck. The recently modified inhalation technique for measuring CBF by ${ }^{133}$ Xenon clearance is already under trial for this purpose in the Institute of Neurological Sciences (Lennox et al., 1975; Wyper et al., 1975). Blood flow in the right and left cerebral hemispheres is compared before and during percutaneous compression 
of the carotid artery in the conscious patient. Effective compression is verified by attaching a pulse monitor to the ear lobe. This test is accompanied by continuous monitoring of the EEG and represents further elaboration of the well-known Matas test. In 14 patients these results could be compared with values obtained during subsequent operative carotid clamping. There was an excellent correlation between the flow changes recorded by the two techniques, so that there does appear to be a prospect for the atraumatic evaluation of the cerebral circulatory response to occlusion of one of its major sources of supply. Our experience suggests that this response may be of importance for determination of outcome not only from carotid ligation but also from intracranial surgery.

That no clear-cut correlation emerged between the rejection rate for carotid ligation and the age or neurological status of the patient suggests, but no more than this, that anatomical rather than physiopathological factors may dominate in determining the adequacy of the collateral circulation to the brain in the event of unilateral carotid occlusion. We have, however, shown previously that angiographically visualised anatomical differences do not have predictive value for the tolerance of carotid ligation (Jawad et al., 1977). It seems likely, therefore, that the variables which affect the cerebral collateral circulation lie at the microvascular level.

This is not to deny the importance of physiological factors, however. Extensive experimental studies in this department have shown that after unilateral or bilateral carotid ligation in baboons there is a marked reduction of the responsiveness and tolerance of the cerebral circulation to changes in arterial $\mathrm{PCO}_{2}, \mathrm{PO}_{2}$, and blood pressure (Sengupta et al., 1973, 1974). Carotid occlusion produces much more pronounced immediate effects in man in that there is a significantly greater fall in CBF and ICAP (Jennett et al., 1974). It is, therefore, reasonable to deduce from these experiments that the cerebral circulation in patients is even more vulnerable to changes in blood gases or blood pressure after carotid ligation. In practice, we have observed patients who developed temporary signs of cerebral ischaemia related to episodes of relatively mild hypoxia or hypotension in the immediate postoperative period. This seems to provide the best explanation so far for the development of delayed hemiparesis after carotid ligation. Observations in the co-operative aneurysm study (Nishioka, 1966) and at the Mayo Clinic (Landolt and Millikan, 1970) indicate that in two-thirds of cases of post-ligation cerebral ischaemia the onset is delayed for hours or even days. When the onset of ischaemia is delayed it is more likely to persist; moreover, such late onset ischaemia cannot be detected by trial carotid occlusion under local anaesthesia with neurological testing, still a widely used method.

By comparison of these clinical and experimental studies it is now possible to place carotid ligation in context in contemporary neurosurgery. For those aneurysms for which carotid ligation remains the only feasible treatment, the use of cerebral blood flow measurements during surgery now permits the surgeon to establish firmly in the individual patient the degree of risk associated with ligation. The risk of ischaemia can then be weighed against the risk of leaving the carotid artery patent and providing no protection against recurrent subarachnoid haemorrhage or progression in the size of an aneurysm. This approach can be applied also to other situations in which the carotid artery may have to be occluded, such as carotid-cavernous fistula, radical surgery of head and neck, trauma to the carotid system, and carotid body tumours. Measurements of CBF have been used to determine the requirement for intraluminal shunts in patients undergoing carotid endarterectomy (Boysen, 1973; Sundt et al., 1974). In this case, the anticipated carotid occlusion is temporary; this is reflected in the lower levels of CBF and carotid pressure which are considered safe. Nevertheless, the approach to the problem is the same.

When the surgeon has the alternative of carotid ligation or direct intracranial surgery for treatment of an aneurysm, trial carotid occlusion with blood flow measurements enables him/her to establish whether it is possible to ligate the carotid artery with minimal risk to the patient. If so, the risks of intracranial surgery have to be matched against this course of action, rather than against the result of no surgery at all. Should blood flow measurements predict intolerance of carotid occlusion the surgeon can avoid carotid ligation; our results suggest (but no more than this) that such patients may run a higher risk of complications after intracranial surgery. Further evidence of this possible implication of these studies is being sought.

Microneurosurgical techniques have already improved the performance and results of aneurysm surgery (Krayenbühl et al., 1972); the next major advance should be the better identification of good and poor risk patients awaiting aneurysm surgery. We believe that one of the crucial factors in such a determination is the status of the cerebral circulation; preoperative and intraoperative studies of cerebral blood flow may add significantly to the safety of aneurysm surgery in this way.

This study forms part of the investigative programme of the Medical Research Council Group for the Study 
of the Cerebral Circulation at the Institute of Neurological Sciences (Director-Professor Bryan Jennett). It has involved the active participation of the Division of Clinical Physics (Mr J. O. Rowan, Dr W. D. Wyper). We wish to thank the other neurosurgeons of the Institute who have referred patients to us for investigation and treatment.

\section{References}

Abernethy, J. (1811). Observations on Injuries of the Head; and on Miscellaneous Subjects, p. 162. Edited by T. Dobson. Philadelphia.

Botterell, E. H., Lougheed, W. M., and Scott, J. W. (1956). Hypothermia and interruption of carotid and vertebral circulation in the surgical management of intracranial aneurysms. Journal of Neurosurgery, 13, 1-24.

Boysen, G. (1973). Cerebral hemodynamics in carotid surgery. Acta Neurologica Scandinavica, 40, suppl. 52, $1-84$.

Graf, C. J., and Nibbelink, D. W. (1974). Co-operative study of intracranial aneurysms and subarachnoid hemorrhage. Report on a randomised treatment study. Part 3. Intracranial surgery. Stroke, 5, 559-601.

Jawad, K., Miller, J. D., Fitch, W., and Barker, J. (1976). Measurement of jugular venous blood gases for prediction of brain ischaemia following carotid ligation. European Neurology, 14, 43-52.

Jawad, K., Miller, J. D., Wyper, D. J., and Rowan, J. O. (1977). Measurements of cerebral blood flow and carotid artery pressure compared with cerebral angiography in the assessment of collateral blood supply to the brain following carotid ligation. Journal of Neurosurgery. (In press.)

Jeffreys, R. V., and Holmes, A. E. (1971). Common carotid ligation for the treatment of ruptured posterior communicating aneurysms. Journal of Neurology, Neurosurgery, and Psychiatry, 34, 576-579.

Jennett, W. B., Harper, A. M., and Gillespie, F. C. (1966). Measurements of regional cerebral blood flow during carotid ligation. Lancet, 2, 1162-1163.

Jennett, B., Miller, J. D., Harper, A. M., Leech, P., and Sengupta, D. (1974). Experimental and clinical studies of cerebral blood flow after carotid ligation. In Pathology of Cerebral Microcirculation, pp. 414-418. Edited by J. Cervos-Navarro. De Gruyter: Berlin.

Keen, W. W. (1890). Intracranial lesions. Medical News (New York), 57, 443.

Krayenbühl, H. A., Yasargil, M. G., and Flamm, E. S. (1972). Microsurgical treatment of intracranial saccular aneurysm. Journal of Neurosurgery, 37, 678-686.

Landolt, A. M., and Millikan, C. H. (1970). Pathogenesis of cerebral infarction secondary to mechanical carotid artery occlusion. Stroke, 1, 52-62.

Leech, P. J., Miller, J. D., and Fitch, W. (1974). Cerebral blood flow, internal carotid artery pressure and the EEG as a guide to the safety of carotid ligation. Journal of Neurology, Neurosurgery, and Psychiatry, 37, 854-862.

Lennox, G. A., Wyper, D. J., and Jawad, K. (1975). A ${ }^{133}$ Xenon inhalation technique for CBF measurement. Normal and abnormal flow patterns. In Blood Flow and Metabolism of the Brain, vol. 8, pp. 12-16. Edited by A. M. Harper, W. B. Jennett, J. D. Miller, and J. O. Rowan. Churchill-Livingstone: Edinburgh.

Nishioka, H. (1966). Report on the co-operative study of intracranial aneurysms and subarachnoid haemorrhage. Section 8, part 1. Results of treatment of intracranial aneurysms by occlusion of the carotid artery in the neck. Journal of Neurosurgery, 25, 660-682.

Paterson, A. (1968). Direct surgery in the treatment of posterior communicating aneurysms. Lancet, 2, 808-811.

Rowan, J. O., Miller, J. D., Wyper, D. J., Fitch, W., Grosshart, K. G., Garibi, J., and Pickard, J. D. (1975). Variability of repeated clinical measurements of CBF using the ${ }^{133}$ Xenon intracarotid injection technique. In Cerebral Circulation and Metabolism, pp. 402-405. Edited by T. W. Langfitt, L. C. McHenry, M. Reivich. and $\mathrm{H}$. Wollman. Springer: Berlin.

Sengupta, R. P. (1972). Carotid ophthalmic aneurysm. Journal of Neurology, Neurosurgery, and Psychiatry, $35,138$.

Sengupta, D., Harper, A. M., and Jennett, B. (1973). Effect of carotid ligation on cerebral blood flow in baboons. 1. Response to altered arterial $\mathrm{PCO}_{2}$. Journal of Neurology, Neurosurgery, and Psychiatry, 35, 736-741.

Sengupta, D., Harper, A. M., and Jennett, B. (1974). Effect of carotid ligation on cerebral blood flow in baboons. 2. Response to hypoxia and haemorrhagic hypertension. Journal of Neurology, Neurosurgery, and Psychiatry, 37, 578-584.

Sundt, T. M., Sharbrough, F. W., Anderson, R. E., and Michenfelder, J. D. (1974). Cerebral blood flow measurements and electroencephalograms during carotid endarterectomy. Journal of Neurosurgery, 41, 310-320.

Tindall, G. T. (1973). Management of aneurysms of anterior circulation by carotid artery occlusion. In Neurological Surgery, vol. 2, pp. 768-786. Edited by J. R. Youmans. Saunders: Philadelphia.

Wyper, D. J., Lennox, G. A., and Rowan, J. O. (1975). A ${ }^{133}$ Xenon inhalation technique for CBF measurement. Theory and normal responses. In Blood Flow and Metabolism of the Brain, vol. 8, pp. 7-11. Edited by A. M. Harper, J. D. Miller, B. Jennett, and J. O. Rowan. Churchill-Livingstone: Edinburgh.

Wyper, D. J., and Rowan, J. O. (1973). An on-line system for acquisition and processing of cerebral blood flow data. Computers in Biology and Medicine, 3, 55-62. 